\title{
Cefazolin sodium pentahydrate combined with vacuum sealing drainage in the treatment of open fracture complicated with soft tissue injury
}

\author{
Wenjie Lou' \\ (iD) Kai Zou ${ }^{1}$ \\ D.Dhongbin Yu ${ }^{1}$ \\ (iD) Song Qin ${ }^{1}$ \\ (iD) Kai Wang ${ }^{1}$ \\ (i) Biao Che ${ }^{1}$
}

1. Department of Orthopedics, General Hospital of the Yangtze River Shipping and Wuhan Brain Hospital, Wuhan 430010, China

http://dx.doi.org/10.1590/1806-9282.66.4.430

\begin{abstract}
SUMMARY
OBJECTIVE: To investigate the clinical efficacy of cefazolin sodium pentahydrate combined with vacuum sealing drainage (VSD) in the treatment of open fracture complicated with soft tissue injury.

METHODS: Sixty-three patients with open fracture complicated with soft tissue injury were divided into observation $(n=33)$ and control $(n=30)$ groups. After surgical reduction, fixation, and repair of the fractures, the control group was treated with VSD for 10 days, and the observation group was treated with cefazolin sodium pentahydrate based on VSD for 10 days. The infection control time was recorded. After treatment, the pain of patients was evaluated. Before and after treatment, the serum levels of C-reactive protein (CRP), interleukin (IL)-6, IL-8, tumor necrosis factor $\alpha$ (TNF- $\alpha$ ), cortisol, epinephrine, norepinephrine, and glucose were detected. After 6 months of treatment, the total effective rate of the treatment was evaluated.

RESULTS: The infection control time and Visual Analogue Scale score after treatment in the observation group were significantly lower than in the control group, respectively $(P<0.05)$. After the treatment, the serum levels of CRP, IL-6,IL-8, TNF- $\alpha$, cortisol, epinephrine, norepinephrine, and glucose in each group were significantly lower than before the treatment $(P<0.05)$, and each index in observation was significantly lower than in the control group $(P<0.05)$.

CONCLUSIONS: In the treatment of open fractures complicated with soft tissue injury, cefazolin sodium pentahydrate combined with VSD can effectively reduce inflammation and stress, thus improving the treatment efficacy.
\end{abstract}

KEYWORDS: Fractures, open. Soft tissue injuries. Cefazolin. Negative-pressure wound therapy.

\section{INTRODUCTION}

In modern society, the incidence of accidents caused by high-energy factors is increasing year by year. Fractures, especially open ones, have become a common and frequently-occurring injury. Open fractures are often accompanied by soft tissue injury, large-area skin defect, and tendon exposure. Soft tissue injury has brought great challenges to the treatment of fractures and is also the key to determine the curative effect. The speed and degree of soft tissue healing determine the outcome of fracture healing and

DATE OF SUBMISSION: 18-Nov-2019

DATE OF ACCEPTANCE: 26-Nov-2019

CORRESPONDING AUTHOR: Biao Che

Department of Orthopedics, General Hospital of The Yangtze River Shipping and Wuhan Brain Hospital, 5 Huiji Road, Jiangan District,

Wuhan 430010, China. Tel.: +86-27-27-82421652

E-mail: chebiaowh@163.com 
limb function preservation ${ }^{1,2}$. At present, open dressing change and skin grafting are often used to promote wound healing. However, many patients are complicated with slow growth of adjacent wound granulation tissue, insufficient blood supply, and local release of toxic substances from necrotic tissue, leading to the infection ${ }^{3,4}$. In addition, the long-term wound exposure, cross-infection, and nosocomial infection are also important factors of further infection ${ }^{5}$. In recent years, the vacuum sealing drainage (VSD) technique has been widely used in orthopedics. It has a definite effect in promoting granulation growth, reducing tissue edema, and improving wound microcirculation. VSD has now become the standard treatment method for some wounds ${ }^{6,7}$. However, some complications may occur when VSD is used alone, such as blockage of the drainage tube and anaerobic bacteria growth caused by anaerobic environment due to wound closure, which leads to the frequent replacement of dressings ${ }^{8}$. Cefazolin sodium pentahydrate is an upgraded variety of the traditional cefazolin sodium. It can further extend the strong anti-gram-positive bacteria performance of cefazolin sodium, and greatly reduce the incidence of adverse reactions, especially allergic ones9. Given this, this study investigated the clinical efficacy of cefazolin sodium pentahydrate combined with VSD in the treatment of open fractures complicated with soft tissue injury. The objective was to provide a reference for further applications of this strategy in the clinic setting.

\section{METHODS}

\section{Patients}

Sixty-three patients with open fracture complicated with soft tissue injury admitted to our hospital from March 2013 to June 2017 were selected. There were 48 males and 25 females. The age of patients was 18 -63 years, with an average of $40.56 \pm 6.12$ years. The course of injury was $1-25 \mathrm{~h}$, with an average of $3.99 \pm 1.43 \mathrm{~h}$. There were 8 cases caused by crashing objects, 15 caused by falling, 22 caused by traffic accidents, and 18 caused by mechanical contusion. There were 26 cases of upper limb injuries and 37 cases of lower limb injuries. According to the Gustilo classification, there were 16 cases of type II, 33 cases of type III A, and 14 cases of type III B. The inclusion criteria were as follows: i) the imaging findings showed the limb fractures; ii) the fracture conformed to the Gustilo classification of open fracture; iii) there was exudate in the wound; iv) there was defined trauma history. The exclusion criteria were as follows: i) allergy to experimental drugs; ii) serious heart, lung, liver, or other important organ dysfunction. This study was approved by the Medical Ethics Committee of the General Hospital of The Yangtze River Shipping, and all the participants signed the informed consent.

\section{Treatment}

After admission, the patients in two groups actively received fluid infusion and antibiotics treatment. The wound was cleaned and disinfected before surgery, and the necrotic tissues or foreign materials were removed. The surgical reduction, fixation, and repair of the fracture were performed according to imaging findings. After the above treatment, the VSD material was cut into the shape of the wound size, and the drainage strip was made by inserting multi-side porous silica gel material into the VSD material. The length of each drainage strip was less than $2 \mathrm{~cm}$. The drainage strips were connected by a three-way joint, and the skin around the wound was disinfected with alcohol. Then, the wound and the drainage strips were sealed together using translucent film. The other outlets of the drainage strips were connected to the negative pressure machine. The pressure of the machine was set at 120-400 mmHg. The continuous drainage was performed for 10 days. If the surgery was successful and the sealing worked well, the VSD material was removed after about 10 days. If the VSD did not reach a good state, it needed to be re-performed in time. From the time of the VSD beginning, the patients in the observation group received an intravenous drip of cefazolin sodium pentahydrate (Shenzhen Jiuxin Pharmaceutical Co., Ltd., Shenzhen, China), with a dose of $2.0 \mathrm{~g} /$ day, for successive 10 days. The patients in the control group received routine treatment only.

\section{Observation of wound situation}

During the treatment, the situation of the wound was observed. The standard of infection control was as follows: i) the bacterial culture results of the sample in three consecutive drainages were negative; ii) the fresh granulation tissue grew well, and the blood supply was good; iii) there was no obvious inflammation such as swelling and exudation around or in the wound. The duration from the beginning of the treatment to the occurrence of the above situations was regarded as the infection control time. 


\section{Evaluation of pain}

After the treatment, the pain of patients was evaluated using the Visual Analogue Scale (VAS) score as follows: 0 points: no pain; $1-3$ points: mild pain; 4-6 points: moderate pain; 7-9 points: severe pain; 10 points: the most severe pain.

Measurement of inflammatory factors and stress indexes

Before and after the treatment, $5 \mathrm{ml}$ of circulating venous blood was collected and serum was obtained after centrifugation. The serum levels of C-reactive protein (CRP), interleukin (IL)-6, IL-8, and tumor necrosis factor $\alpha$ (TNF- $\alpha$ ) were detected by enzymelinked immunosorbent assay. The serum levels of cortisol, epinephrine, and norepinephrine were detected by high-performance liquid chromatography and electrochemical methods. The level of glucose was detected by the glucose oxidase method.

Follow up and evaluation of total treatment efficacy

The patients were followed up for 6 months. The total curative effect was evaluated at the end of the follow up as follows: i) cured: X-ray examination showed that the bone destruction was repaired; the dead bone disappeared; the local swelling and pain disappeared; the systemic symptoms disappeared; the sinus ulcer was healed; the limb function recovered; ii) markedly effective: X-ray showed that partial bone destruction was repaired and the lesion was improved; the local swelling and pain disappeared; the systemic symptoms were alleviated; the sinus ulcer was healed; the limb function was improved; iii) effective: X-ray showed that the bone destruction tended to be repaired and the lesion was stable; the local and systemic symptoms were improved; the sinus ulcer was not healed, with sinus tract residue; iv) ineffective: X-ray showed that the lesion continued to develop; the local and systemic symptoms could not be controlled. The total effective (cured + markedly effective + effective) rate was calculated.

\section{Statistical analysis}

SPSS statistical package (SSPS Inc., Chicago, USA) version 20.0 was used to perform the statistical analysis. The measurement data were presented as mean $\pm \mathrm{SD}$, and the comparison between the two groups and between before and after treatment was performed using the t-test. The enumeration data were presented as a number, and the comparison was performed using the chi-square $\left(\chi^{2}\right)$ test. $\mathrm{P}<0.05$ was defined as statistically significant.

\section{RESULTS}

General data of the subjects in the two groups

The general data of the subjects in the observation and control groups are shown in Table 1. Each index of age, gender, injury course, cause of injury, injury site, and Gustilo classification had no significant difference between two groups $(\mathrm{P}>0.05)$.

TABLE 1. GENERAL DATA OF SUBJECTS IN THE TWO GROUPS.

\begin{tabular}{|c|c|c|c|c|}
\hline Group & Observation & Control & $t / \chi^{2}$ & $\mathrm{P}$ \\
\hline$n$ & 33 & 30 & & \\
\hline Age (years) & $41.22 \pm 5.19$ & $39.78 \pm 4.73$ & 1.147 & 0.256 \\
\hline Gender (male/female, $n$ ) & $20 / 13$ & $18 / 12$ & 0.002 & 0.961 \\
\hline Injury course (h) & $3.75 \pm 1.33$ & $4.12 \pm 1.63$ & 1.125 & 0.265 \\
\hline Cause of injury (n) & & & 0.607 & 0.895 \\
\hline Crashing object & 5 & 3 & & \\
\hline Falling & 7 & 8 & & \\
\hline Traffic accident & 12 & 10 & & \\
\hline Mechanical contusion & 9 & 9 & & \\
\hline Injury site $(n)$ & & & 0.038 & 0.845 \\
\hline upper limb & 14 & 12 & & \\
\hline lower limb & 19 & 18 & & \\
\hline Gustilo classification (n) & & & 0.174 & 0.917 \\
\hline Type II & 8 & 8 & & \\
\hline Type IIIA & 17 & 16 & & \\
\hline Type IIIB & 8 & 6 & & \\
\hline
\end{tabular}




\section{Comparison of infection control time and VAS score between the two groups}

The infection control time in the observation group was $2.32 \pm 0.44$ days, which was significantly shorter than the $10.45 \pm 2.78$ days in the control group $(\mathrm{P}<0.05)$. After the treatment, the VAS score in the observation group was $2.32 \pm 0.44$ points, which was significantly lower than the $2.66 \pm 0.55$ points in the control group $(\mathrm{P}<0.05)$.

\section{Comparison of serum inflammatory factors} between the two groups

Before the treatment, the serum levels of CRP, IL-6, IL- 8 , and TNF- $\alpha$ had no significant difference between observation and control groups, respectively $(\mathrm{P}>0.05)$. After the treatment, the serum levels of CRP, IL-6, IL-8, and TNF- $\alpha$ in each group were significantly lower than those before treatment, respectively $(\mathrm{P}<0.05)$. In addition, after the treatment, each index in the observation group was significantly lower than those in the control group $(\mathrm{P}<0.05)$ (Figure 1).

\section{Comparison of serum stress indexes between} the two groups

Before the treatment, there was no significant difference in serum levels of cortisol, epinephrine, norepinephrine, or glucose between the observation and control groups, respectively $(\mathrm{P}>0.05)$. After the treatment, the serum levels of cortisol, epinephrine, norepinephrine, and glucose in each group were significantly lower than those before the treatment $(\mathrm{P}<$ 0.05). In addition, after the treatment, each index in the observation group was significantly lower than that in the control group $(\mathrm{P}<0.05)$ (Figure 2).

\section{Comparison of adverse reactions between the two groups}

During the treatment, the main adverse reactions of patients were gastrointestinal reactions, low fever, rash, and others. The incidence of adverse reactions in the observation and control groups was $2.67 \%$ and $4.45 \%$, respectively, with no significant difference between the two groups $(\mathrm{P}>0.05)$.

\section{Follow up results}

After 6 months from the treatment, in the observation group, there were $11,16,5$, and 1 cases with cured, remarkably effective, effective, and ineffective treatment outcomes, respectively. In the control group, there were 9, 14, 4, and 3 cases with cured, remarkably effective, effective, and ineffective treatment outcomes in the control group, respectively. The total effective rates in the observation and control groups were $96.97 \%$ and $90.00 \%$, respectively, with no significant difference between the two groups $(\mathrm{P}$ $>0.05)$.

\section{DISCUSSION}

In open fractures, the injured tissues are exposed to air for a long time. This is prone to cause the incomplete removal of remnants and necrotic tissues and ischemia of the wound margin. Therefore, the chance of wound infection is higher than in closed injuries10. In the traditional treatment of open fractures complicated with soft tissue injury, based on the surgical reduction, fixation, and repair of fracture, the strict debridement, thorough hemostasis, smooth drainage, and prophylactic application of antibiotics are often conducted. However, the incidence of postoperative infections in traditional treatment is still high ${ }^{11}$. In VSD, based on traditional debridement, the wound is filled with the dressing to close the dead cavity. A continuous negative pressure sealing environment is constructed by drainage through silica gel tubes and closure of the wound with physiological-permeability adhesive film. This can thoroughly remove the necrosis and exudates ${ }^{12}$. The VSD material has good histocompatibility and is not easy to adhere to. At the same time, VSD can reduce the number of dressing changes, the chances of cross-infection, and the pain and economic burden of patients ${ }^{13}$. Cefazolin sodium pentahydrate is developed based on cefazolin sodium. Its chelating crystal structure is more refined and stable. All sulfur-containing groups are firmly encapsulated in the crystal, which can effectively prevent the falling off of sulfur-containing groups and their contact with rubber plugs, producing toxic substances ${ }^{14}$. Cefazolin sodium pentahydrate has a more remarkable antimicrobial effect and higher safety compared with cefazolin sodium. There are fewer reports on the application of cefazolin sodium pentahydrate for patients with open fractures complicated with soft tissue injury. This study investigated the clinical efficacy of cefazolin sodium pentahydrate combined with VSD in the treatment of open fractures complicated with soft tissue injury. Results showed that, compared with using VSD alone, cefazolin sodium pentahydrate combined with VSD could shorten the infection control time and decrease the VAS score. This indicates 


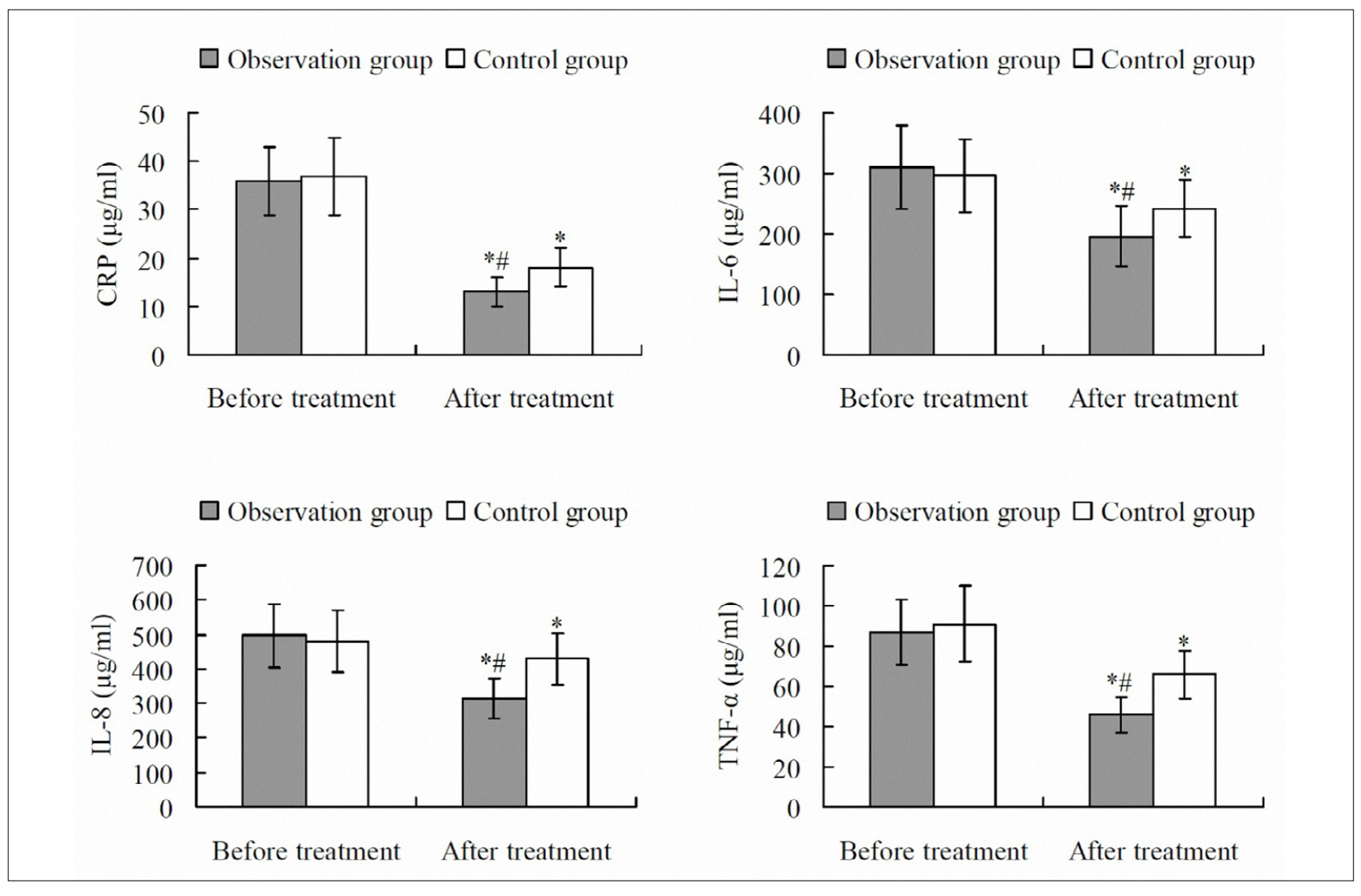

FIGURE 1. SERUM INFLAMMATORY FACTORS BEFORE AND AFTER TREATMENT IN THE TWO GROUPS. ${ }^{*}<0.05$ COMPARED WITH BEFORE THE TREATMENT; \#P < 0.05 COMPARED WITH THE CONTROL GROUP. CRP, C-REACTIVE PROTEIN; IL-6, INTERLEUKIN 6; IL-8, INTERLEUKIN 8; TNF- $\alpha$, TUMOR NECROSIS FACTOR $\alpha$.

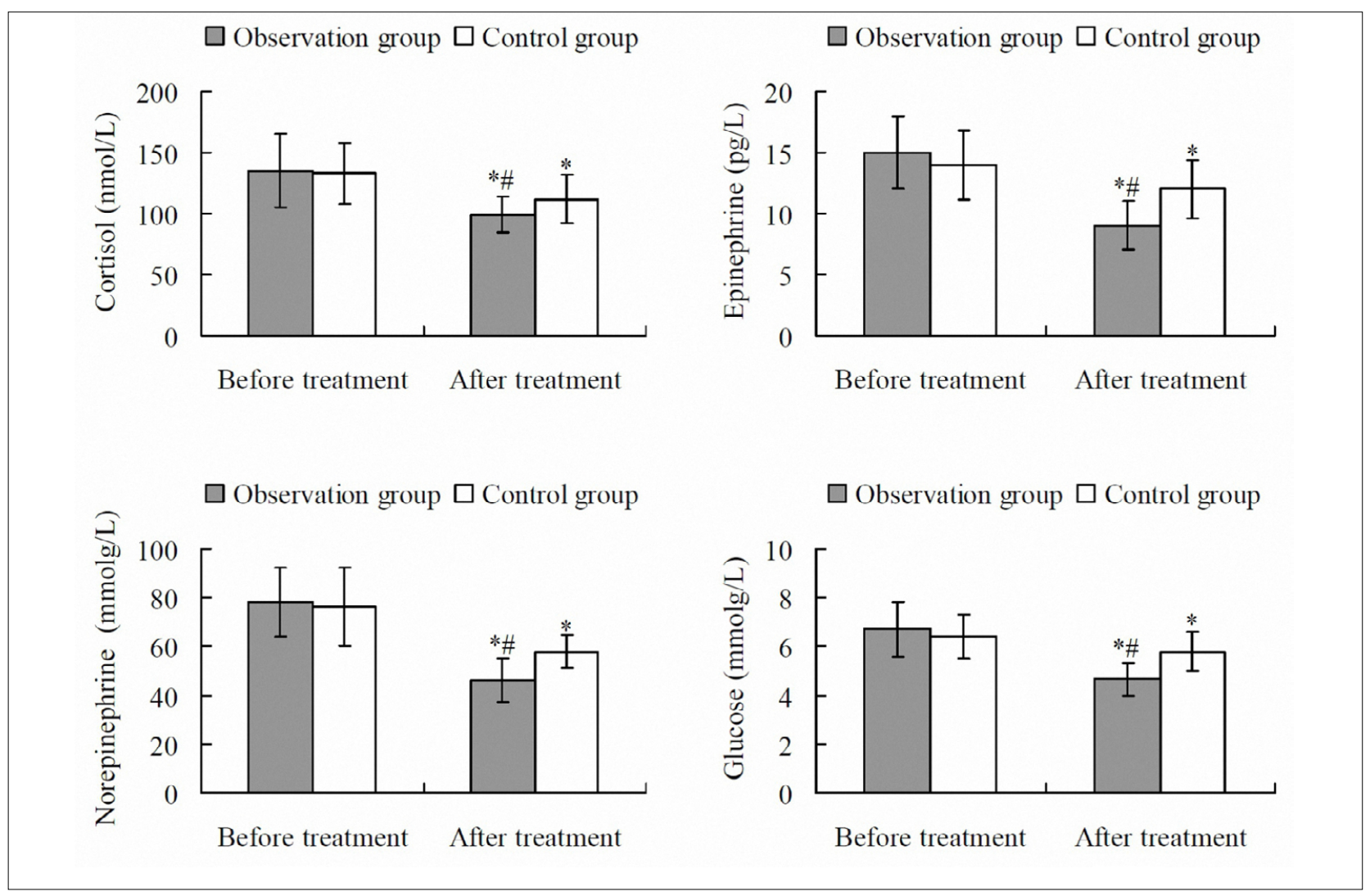

FIGURE 2. SERUM STRESS INDEXES BEFORE AND AFTER THE TREATMENT IN THE TWO GROUPS. "P $<0.05$ COMPARED WITH BEFORE THE TREATMENT; \#P < 0.05 COMPARED WITH THE CONTROL GROUP. 
that, in treating open fractures complicated with soft tissue injury, the combination of cefazolin sodium pentahydrate and VSD can clearly improve the efficacy, compared with using VSD alone.

In open fracture patients, due to tissue injury, surgical trauma, and postoperative infection, the serum levels of inflammatory factors dramatically increase. CRP, IL-6, IL-8, and TNF- $\alpha$ are common inflammatory factors synthesized by peripheral macrophages, lymphocytes, fibroblasts, and other immune cells. Moreover, they interact with each other. The increase in the level of one inflammatory factor can promote the synthesis and secretion of other inflammatory factors through a cascade reaction ${ }^{15}$. These inflammatory factors can promote the release of prostaglandin $\mathrm{E} 2$, collagenase, and a large number of proteoglycan enzymes to destroy the cartilage matrix and aggravate the inflammatory reaction, which is not conducive to the prognosis of patients ${ }^{16}$. Results of this study showed that, after the treatment, the serum levels of inflammatory factors in each group were significantly lower than before the treatment, each index in the observation group was significantly lower than that in the control group. This suggests that the combination of cefazolin sodium pentahydrate and VSD can further reduce the inflammation reaction.

Trauma, surgery, and inflammatory reaction can induce a systemic stress response. Cortisol is an important hormone in the body, which can effectively maintain normal physiological functions and plays an important role in regulating mood and health, cellular immunity, and inflammation. When the body is in a state of stress, cortisol levels rise significantly to maintain the stability of blood pressure ${ }^{17}$. In addition, excessive cortisol secretion can induce increased glycogen decomposition, leading to an increase in blood glucose level ${ }^{18}$. Under a stress state, the excitability of the sympathetic nerves is increased, and the synthesis and secretion of epinephrine and norepinephrine are significantly increased ${ }^{19}$. In the present study, after the treatment, the serum levels of cortisol, epinephrine, norepinephrine, and glucose in the observation group were significantly lower than in the control group. This indicates that the combination of cefazolin sodium pentahydrate and VSD can further decrease the stress response in patients with open fractures complicated with soft tissue injury.

In conclusion, in the treatment of open fractures complicated with soft tissue injury, cefazolin sodium pentahydrate combined with VSD can effectively reduce inflammation and stress, thus improving the treatment effect. It is a safe and efficient treatment strategy and is worthy of further study and application. This study still has some limitations. The sample size is relatively small, and a larger sample size will make the results more convincing. In our next studies, the sample size should be further increased for more satisfactory outcomes. In addition, there may be changes of other factors involved in open fractures complicated with soft tissue injury, which need to be further clarified.

\section{Declaration of conflict of interest}

None.

\section{Authors' contributions}

Biao Che and Kai Zou designed the study. Wenjie Lou and Zhongbin Yu participated in data collection. Biao Che and Song Qin performed statistical analyses. Wenjie Lou drafted the manuscript. Biao Che and Kai Wang critically revised the manuscript. All authors read and approved the final manuscript.

\section{Acknowledgements}

This work was supported by Yangtze River Administration of Navigational Affairs (No. 201810009).

\section{RESUMO}

OBJETIVO: Investigar a eficácia clínica do cefazolin penta-hidrato de sódio combinado com drenagem por vedação a vácuo (VSD) no tratamento da fratura exposta complicada com lesão nos tecidos moles.

MÉTODOS: Sessenta e três doentes com fratura exposta complicada com lesões nos tecidos moles foram divididos em grupos de observação $(n=33)$ e controle $(n=30)$. Após redução cirúrgica, fixação e reparação da fratura, o grupo de controle foi tratado com VSD durante dez dias e o grupo de observação foi tratado com cefazolina penta-hidrato de sódio com base no VSD durante dez dias. O tempo de controle de infecção foi gravado. Após o tratamento, a dor dos doentes foi avaliada. Antes e após o tratamento, foram detectados os níveis séricos de proteína C-reativa (CRP), interleucina (IL)-6, IL -8, fator de necrose tumoral alfa (TNF- $\alpha$ ), cortisol, epinefrina, norepinefrina e glicose. Após seis meses de tratamento, a taxa efetiva total de tratamento foi avaliada. 
RESULTADOS: O tempo de controle da infecção e a pontuação da Escala Visual Analógica após o tratamento no grupo de observação foram significativamente inferiores ao do grupo de controle, respectivamente $(P<0,05)$. Após o tratamento, os níveis séricos de CRP, IL-6, IL-8, TNF- $\alpha$, cortisol, epinefrina, norepinefrina e glicose em cada grupo foram significativamente menores do que antes do tratamento, respectivamente $(P<0,05)$, e cada índice de observação foi significativamente inferior ao do grupo de controle $(P<0,05)$.

CONCLUSÃO: No tratamento da fratura exposta complicada com lesões nos tecidos moles, o cefazolin penta-hidrato de sódio combinado com VSD pode efetivamente reduzir a inflamação e o estresse, melhorando assim a eficácia do tratamento.

PALAVRAS-CHAVE: Fraturas expostas. Lesões dos tecidos moles. Drenagem a vácuo. Cefazolina. Tratamento de ferimentos com pressão negativa.

\section{REFERENCES}

1. Kobbe P, Vodovotz Y, Kaczorowski DJ, Billiar TR, Pape HC. The role of fracture-associated soft tissue injury in the induction of systemic inflammation and remote organ dysfunction after bilateral femur fracture. J Orthop Trauma. 2008;22(6):385-90.

2. Friedrich JB, Katolik LI, Hanel DP. Reconstruction of soft-tissue injury associated with lower extremity fracture. J Am Acad Orthop Surg. 2011;19(2):81-90.

3. Kim YH, Hwang KT, Kim JT, Kim SW. What is the ideal interval between dressing changes during negative pressure wound therapy for open traumatic fractures? J Wound Care. 2015;24(11):536, 538-40, 542.

4. Mansha M, Sharif K, Sharif Z, Kashif FA, Diggory P. The impact of different methods of wound closure and dressing on the rate of wound infection in patients with fracture of the neck of femur. J Orthop Nurs. 2005;9(4):195-8.

5. Pollard TC, Newman JE, Barlow NJ, Price JD, Willett KM. Deep wound infection after proximal femoral fracture: consequences and costs. J Hosp Infect. 2006;63(2):133-9.

6. Li RG, Yu B, Wang G, Chen B, Qin CH, Guo G, et al. Sequential therapy of vacuum sealing drainage and free-flap transplantation for children with extensive soft-tissue defects below the knee in the extremities. Injury. 2012;43(6):822-8.

7. Shi B, Sun J, Cao Y, Yang F, Wu Y, Liang X, et al. Application of vacuum sealing drainage to the treatment of seawater-immersed blast-injury wounds. Int Wound J. 2016;13(6):1198-205.

8. Cheng $L$, Chai Y. Analysis of vacuum sealing drainage complications during treatment of extremity wounds. Zhongguo Xiu Fu Chong Jian Wai Ke Za Zhi. 2010;24(11):1354-6.

9. Yang J, Ma Z, Qiu C, Yang J, Li S, Su L, et al. Clinical trial of cefazolin sodium pentahydrate in the treatment of acute respiratory tract bacterial infections. Chin I Clin Pharmacol. 2006;22(3):326-8.

10. Jenkinson RJ, Kiss A, Johnson S, Stephen D|, Kreder HJ. Delayed wound closure increases deep-infection rate associated with lower-grade open fractures: a propensity-matched cohort study. J Bone Joint Surg Am. 2014;96(5):380-6.
11. Thanni LO, Aigoro NO. Surgical site infection complicating internal fixation of fractures: incidence and risk factors. J Natl Med Assoc. 2004;96(8):1070-2.

12. Hao S, Juan L, Xin W. Treatment of traumatically cutaneous necrosis of buttocks using vacuum sealing drainage combined with ileostomy. Eur J Trauma Emerg Surg. 2016;42(1):87-90.

13. Ni J, Liu H, Liu X, Zhou L, Sun $Y$, Shi P, et al. Vacuum sealing drainage as treatment of severe buttocks and perianal infection: a case report and review of the literature (care-compliant). Medicine (Baltimore). 2015;94(43):e1766.

14. Tian Y, Wang WD, Zou WB, Qian JQ, Hu CQ. Application of solid-state NMR to reveal structural differences in cefazolin sodium pentahydrate from different manufacturing processes. Front Chem. 2018;6:113.

15. Abdel-Hafez NM, Saleh Hassan Y, El-Metwally TH. A study on biomarkers, cytokines, and growth factors in children with burn injuries. Ann Burns Fire Disasters. 2007;20(2):89-100.

16. Choi HM, Lee YA, Lee SH, Hong SJ, Hahm DH, Choi SY, et al. Adiponectin may contribute to synovitis and joint destruction in rheumatoid arthritis by stimulating vascular endothelial growth factor, matrix metalloproteinase-1, and matrix metalloproteinase- 13 expression in fibroblast-like synoviocytes more than proinflammatory mediators. Arthritis Res Ther. 2009;11(6):R161.

17. Jaremka LM, Glaser R, Loving T], Malarkey WB, Stowell JR, Kiecolt-Glaser JK. Attachment anxiety is linked to alterations in cortisol production and cellular immunity. Psychol Sci. 2013;24(3):272-9.

18. WaldhäusI WK, Bratusch-Marrain P, Komjati M, Breitenecker F, Troch I. Blood glucose response to stress hormone exposure in healthy man and insulin dependent diabetic patients: prediction by computer modeling. IEEE Trans Biomed Eng. 1992;39(8):779-90.

19. McGuinness OP, Shau V, Benson EM, Lewis M, Snowden RT, Greene $\mathrm{J}$, et al. Role of epinephrine and norepinephrine in the metabolic response to stress hormone infusion in the conscious dog. Am | Physiol. 1997;273(4):E674-81. 